\title{
The Rising Cost of Digital Evidence and its Hidden Fees
}

Hisham Abbas*

Co-Founder of CaseGuard, Sterling, VA 20164, USA

"Corresponding author: Co-Founder of CaseGuard, Sterling, VA 20164, USA, Tel: 2026510957; E-mail: hisham.abbas@gmail.com

Rec date: June 26, 2015 Acc date: June 29, 2015 Pub date: July 02, 2015

Copyright: $\odot 2015$ Abbas $\mathrm{H}$. This is an open-access article distributed under the terms of the Creative Commons Attribution License, which permits unrestricted use, distribution, and reproduction in any medium, provided the original author and source are credited.

\section{Opinion}

With the sheer volume of digital evidence, and its storage costs, rising exponentially in the past few years, some law enforcement decision makers are beginning to ask questions. Most of these questions are in direct response to ever increasing budget cuts.

In this blog post, we'll try to answer some of these common asked questions one by one. We'll do the math for you, talk about the advantages and disadvantages of each solution, and let you decide which solution best fits your needs and your budget. For the purposes of our discussion, we'll assume you're a mid-size agency with 100 officers [1].

\begin{tabular}{|c|c|c|c|c|c|c|c|}
\hline & $\begin{array}{l}\text { Number } \\
\text { officers }\end{array}$ & $\begin{array}{l}\text { Number } \text { of } \\
\text { Cases } \\
\text { Year }\end{array}$ & Quantity & 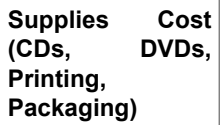 & $\begin{array}{l}\text { Officer } \\
\text { labor cost }\end{array}$ & $\begin{array}{l}\text { Evidence } \\
\text { Tech labor } \\
\text { cost }\end{array}$ & Total Cost \\
\hline CDs/DVDs & 100 & 24 & 2400 & $\$ 0.75$ & $\$ 4.00$ & $\$ 3.00$ & $\$ 18,600.00$ \\
\hline Documents (Digital Format) & 100 & 12 & 1200 & $\$ 0.25$ & $\$ 4.00$ & $\$ 3.00$ & $\$ 8,700.00$ \\
\hline $\begin{array}{l}\text { CDs/DVDs transferred to Court or } \\
\text { Prosecutor's }\end{array}$ & & & 900 & $\$ 0.75$ ( $\times 2$ copies $)$ & & $\$ 1.50$ & $\$ 2,700.00$ \\
\hline Total Cost Per Year & & & & & & & $\$ 30,000.00$ \\
\hline
\end{tabular}

Table 1: Assuming and calculating using CDs/DVDs in one quarter of cases going to prosecutor or court.

If you have 100 sworn officers you're throwing away $\$ 30000$. If you have 200 sworn officers, the cost could exceed $\$ 60000$ ! Not only are you wasting money, the officers' time could be better spent on patrol, making your streets safer.

There are vendors who are offering a cloud based digital evidence management system. They only charge $\$ 40$ per month, per officer, for $15 \mathrm{~GB}$ worth of data and we don't have to deal with any IT management issues. Are we paying too much?

This model, on the surface, appears to be inexpensive and easy. What the vendor didn't tell you was that $15 \mathrm{~GB}$ each is horribly inadequate, especially when one considers that most digital evidence will need to be stored for an average of 3 years before it can be disposed. Think of it this way, limiting your officers to $15 \mathrm{~GB}$ over 3 years $(15 \mathrm{~GB} / 1095$ days $=13.6 \mathrm{MB})$ equals less than one picture a day taken by an IPhone. A large homicide case alone can mean thousands of pictures. Can you imagine what that a case like that would cost you if you use a cloud based solution with caps on usage additional storage fees for excess use? That same vendor will probably offer a solution for you, paying an extra $\$ 15$ per month per officer to get unlimited storage! We've done the math for you here. Again, this is assuming you have 100 sworn officers (Table 2).
We've been using CDs/DVDs and agency computers to store our digital evidence and we haven't had any problems so far. Isn't that the cheapest solution?

Before we start discussing the costs related to this solution, Read "Problems with using CDs/DVDs to store digital evidence" blog post [2]. There are many other problems that could occur when using CDs/ DVDs but let's focus on the cost. Assuming you have 100 sworn officers in your agency and each officer will handle 24 cases a year involving digital evidence (we're pretty sure they get much more than that) and assuming that one quarter of those cases will go to the prosecutor or court, we have the following calculations: (Table 1). 
Page 2 of 2

in the PD headquarters. Think of the time commitment for IT personnel (which is, by the way, very expensive) running around to 100 computers to install a piece of software. Even if it can be done remotely, it takes time and money. What makes this solution even less attractive is when a new update for the software, or a bug fix, is available. Now your IT folks will have to visit these 100 computers one more time to install the update or deploy the fix. We have found that Windows based solutions licenses are way more expensive than web based solution licenses (although we didn't understand why), so even if the base product looks cheap, these licenses will raise the price to match or even surpass the web based solution cost. $\$ 57,000$ for outdated technology? (Table 3 ).

\begin{tabular}{|l|l|l|l|l|l|}
\hline & $\begin{array}{l}\text { Number of } \\
\text { Computers }\end{array}$ & $\begin{array}{l}\text { Number of } \\
\text { Hours per } \\
\text { Computer } \\
\text { per Year }\end{array}$ & $\begin{array}{l}\text { Total } \\
\text { Hours }\end{array}$ & $\begin{array}{l}\text { Cost of } \\
\text { IT hour } \\
\text { or } \\
\text { License }\end{array}$ & Total Cost \\
\hline IT Hours & 100 & 6 & 600 & $\$ 45.00$ & $\$ 27,000.00$ \\
\hline Licenses & 100 & & & $\$ 300.00$ & $\$ 30,000.00$ \\
\hline Total & & & & & $\$ 57,000.00$ \\
\hline
\end{tabular}

Table 3: Assuming computers and working hours with cost.

We are considering a standalone digital evidence management system since we already have a system in place for our physical evidence. Why would we spend the money on a fancy "all in one" system for both physical and digital evidence management systems?

There are very few technical reasons to prevent implementation of a solution like this, but from strictly a cost and convenience perspective, why would you want to deal with two different vendors and pay yearly support to both? It's definitely going to be more expensive. Digital evidence is every bit as important as physical evidence and there are vendors in the market today who are offering one solution for both. Save your time, and money and get one system. If the vendor offers only a digital management system or if his evidence system is not adequate to handle your physical evidence needs, you should probably think twice before committing.

We figured that the best solution is to get a fully web based digital evidence management system. It's a little old fashioned and hard to use, but the vendor has been doing it for many years. Hard to use and old fashioned software shouldn't stop us from investing in it, right?

We believe the best and most cost effective solution is a fully web based evidence management system that can handle your physical as well as digital evidence, hosted on your own agency servers. If you are paying an aftermarket price for this solution then it's ok to use aftermarket software. If you are paying a premium price, you should expect premium software. Old fashioned software is often not well designed, not intuitive, hard to use, not configurable, supports internet explorer only, doesn't work on Chrome or Safari, lacks responsive design, doesn't work on mobile devices and is not user friendly. Web software technologies are fast and ever evolving technologies. Any decent software should keep up with the latest technologies.

In the 1990s, responsive design wasn't even known, nor was configurable software. Today, with many available devices, screens, browsers, and technologies it is important that the software you choose will be operational, user friendly, fast and reliable. If it was designed well, expect it to work on mobile devices just as well as it works on a 70 inch TV monitor. If the vendor is still stuck in the 20th century, look around, there are much more powerful solutions for much cheaper prices.

\section{Conclusion}

In conclusion, we've studied and evaluated the market solutions and discussed digital evidence management systems weaknesses and costs. There are new, state of the art solutions available on the market today which avoid all of the problems discussed in this article and, better yet, they cost less! Before committing your time and money to an evidence management solution, look carefully and evaluate all of your options to make sure your citizens' tax dollars are well spent.

\section{References}

1. http://caseguard.com/blog/The-rising-cost-of-Digital-Evidence-and-itshidden-fees\#sthash.fnnnk0DD.dpuf.

2. http://caseguard.com/blog/Problems-With-Using-CDs-DVDs-To-StoreDigital-Evidence. 